\title{
Brincar na educação infantil como experiência de cultura e formação para a vida
}

Play in childhood education as a cultural experience and formation for life

\author{
Maria Elisa Nicolielo* \\ Universidade Federal de São Carlos \\ Aline Sommerhalder** \\ Universidade Federal de São Carlos \\ Fernando Donizete Alves*** \\ Universidade Federal de São Carlos
}

Resumo $\mathrm{O}$ artigo resulta de uma pesquisa acadêmica concluída cujo objetivo foi conhecer e compreender o que crianças ensinam e aprendem na prática social de brincar na educação infantil. De abordagem qualitativa, a pesquisa teve observação participante, com registros em diário de campo, dos momentos de brincadeira livre de 14 crianças com idade média de três anos e sua professora, em uma sala de educação infantil pública. Realizou-se a discussão na perspectiva qualitativa, à luz do referencial teórico, a partir de três eixos de análise. Os resultados revelaram que ao brincarem juntas, as crianças experienciaram momentos de partilha e negociação de brinquedos e brincadeiras, fortaleceram laços de amizade, manifestaram preferências e ideias, construíram estratégias para a dinâmica da brincadeira, vivenciando oportunidades de formação para a vida.

PALAVRAS-CHAVE: Primeira infância; Brincar; Relações sociais.

\begin{abstract}
The article is the result of an academic research completed that aimed to know and understand what children teach and learn in social practice to play in early childhood education. The research was participant observation, in the qualitative approach with daily records of course, moments of play free of 14 children with an average age of three years and their teacher in a public early childhood education room. It held a discussion on the qualitative perspective, in light of the theoretical framework, based on three axes of analysis. The results showed that when playing together, children experienced moments of sharing and bargain of toys and play, strengthened bonds of friendship, expressed preferences and ideas, were created strategies to the dynamics of the play, experiencing formation opportunities for life.
\end{abstract}

KEYWORDS: Early childhood; Play; Social relationships. 


\section{Introdução}

$\mathrm{O}$ artigo em questão origina-se de uma pesquisa acadêmica e tece considerações sobre processos de ensinar e de aprender que ocorrem entre crianças na prática social da brincadeira livre na educação infantil. Compreendem-se os processos de ensinar e de aprender desencadeados em práticas sociais ${ }^{1}$, a partir do que Sommerhalder e Alves (2011, p. 29) explicitam: "A perspectiva educativa retratada representa um sentido ampliado, para além da transmissão de um conjunto de saberes escolares. É educar para a vida [...]". Isso impõe compreender o ato educativo como aquele que se realiza na intersubjetividade, no caráter inter-humano, é uma técnica essencialmente humana.

$\mathrm{Na}$ sociedade brasileira atual há uma cobrança cada vez mais forte pela produtividade e, neste contexto, as crianças da educação infantil são preparadas para as etapas seguintes de escolarização, visando garantir uma melhor atuação futura no mercado de trabalho e na própria economia brasileira. Este modo de compreensão se expressa, por exemplo, quando brincar não se faz cotidianamente presente na escola ou é aproveitado, sobretudo, como recurso de ensino para o trabalho com os conteúdos. Distancia-se de uma proposta que defende o brincar como uma prática social legítima das crianças e que promove interações e aprendizagens amplas entre estas e destas com os adultos. Nesta ação, as crianças têm oportunidade de conviver com o outro humano e com isso, apropriar-se da cultura ${ }^{2}$ mais ampla, conhecer a realidade e aprender a viver a vida.

Com as proposições das Diretrizes Curriculares Nacionais para a Educação Infantil (BRASIL, 2010) as instituições para a primeira infância tem o objetivo de garantir às crianças acesso a processos de apropriação do conhecimento e aprendizagens, a partir de práticas que tenham como eixos norteadores as interações e a brincadeira. No entanto, assiste-se com profundidade na marginalidade do brincar, materializado pela diminuição de oportunidades de brincar em diversos espaços sociais, majoritariamente na escola, especialmente no modo da brincadeira livre, que proporciona de forma ampliada oportunidades para a criança escolher do quê, com quem e como brincar, fantasiar, dar e emitir significado as vivências da realidade, entender as diversidades da vida real possibilitando, enfim, aprendizagens para a vida. A educação em contexto escolar fica cada vez mais distante das considerações a respeito do lúdico e da fantasia.

Brincar livre, também conhecido como jogo recreativo, quando é possibilitado nas escolas aproxima-se de uma ideia de necessária ação de relaxamento e descanso infantil, justificando a oferta entre uma atividade (trabalho pedagógico sério) e outra (EMERIQUE, 2003). Para o capitalismo, a brincadeira livre ou recreativa é improdutiva, pois a partir dela, as crianças nada produzem e, portanto não aprendem, caracterizando-a como atividade não séria (SOMMERHALDER e ALVES, 2011). Ao propor desta maneira, a escola corrobora com a ideia de criança como um não sujeito, não competente para viver o momento atual de sua vida e pode, com isso, não valorizar de forma significativa ou propiciar com intensidade oportunidades lúdicas. Freire (2005) ensina que é fundamental reconhecermos o ser humano enquanto um ser de relações que está no mundo e com o mundo. Isto implica afirmar que a posição do ser humano no mundo não é de passividade e sim de criação e transformação. 
Brincar é a linguagem da criança por excelência e que se encontra cada vez mais desvalorizada, em decorrência de sua oposição ao mundo do trabalho e da produção. Ao reconhecer as inúmeras linguagens das crianças compreende-se que estas são sujeitos do hoje, sujeitos de direitos e não um projeto de humano para o futuro. O estudo realizado por Santos Neto, Alves e Silva (2011) se aproxima da concepção pensada por Dornelles (2008), ao buscar entender a infância nas obras de Paulo Freire, propondo uma Pedagogia da Infância Oprimida. De acordo com esses autores (2011), o sistema capitalista tem oprimido as infâncias e exigido, daqueles que querem manter a sociedade como está, que saibam tudo sobre elas, para combatê-las. E este combate pode ocorrer nas escolas, nas agendas superlotadas, na ausência de tempo e espaço para brincar, nas diversas formas de violência, na exploração infantil, na exacerbação do consumismo capitalista. "A infância é a força rebelde e primitiva que deve ser catequizada ou domesticada para que o adulto, comprometido com as regras sociais e civilizatórias, emerja”. (OLIVEIRA, 2006, p. 87).

As experiências com o mundo são intermediadas pelas linguagens, ou seja, pelas brincadeiras, pintura, dança, gestos e, são estas linguagens que possibilitam o humano viver a vida e ter oportunidades para compreender, ressignificar e conviver melhor com as diferenças culturais e sociais (GOBBI e PINAZZA, 2014). Por isso, Brougère (2010, p. 110) se refere ao brincar como "[...] espaço de aprendizagem cultural fabuloso e incerto". Friedmann (2013) destaca que, a partir das linguagens infantis descortinam-se as singularidades das crianças, suas essências em profundidade. Esta autora (2013) aponta que a construção destas linguagens inicia nas brincadeiras.

De acordo com Borba (2007) a brincadeira, então, é espaço para novas formas de criação e significação e permite às crianças compreenderem o mundo e a si mesmas. A educação não diz respeito a um único campo de atividade, como as escolares, mas podem estar presentes em atividades que visam outras finalidades, como o caso do lúdico (BROUGÈRE, 2002). Para o autor, a pessoa se forma nas diversas situações vividas em nosso cotidiano e "[...] pode-se pensar que é nestas circunstâncias que se recebe o essencial do que é aprendido" (BROUGÈRE, 2002, p. 13).

Sendo assim, é urgente na contemporaneidade dar maior visibilidade para as brincadeiras das crianças, criadas e organizadas por elas e publicar sobre esta prática social, anunciando seus processos de ensinar e de aprender. Estes processos educativos que, muitas vezes, podem estar relacionados aos conteúdos e atividades vistos pelo(a) professor(a) como aqueles relacionados às experiências de viver a vida, de humanização e de cultura.

Considerando a problemática apresentada em relação à prática social do brincar livre em contextos de educação infantil, interrogou-se: O que crianças ensinam e aprendem em momentos de brincadeira livre, que ocorrem em contexto de Educação Infantil? O objetivo principal foi conhecer e compreender que processos de ensinar e de aprender se desenvolvem nas relações entre crianças e entre elas e o/a professor/a em momentos de brincar livre, na Educação Infantil. 


\section{Percurso metodológico}

A pesquisa teve caráter qualitativo, pois abordou "[...] o conjunto das expressões humanas constantes nas estruturas, nos processos, nos sujeitos, nos significados e nas representações" (MINAYO, 1994, p. 15). Realizou-se pesquisa de campo com 14 crianças ( 8 meninas e 6 meninos) com idade média de três anos matriculadas no Maternal $\mathrm{II}^{3}$ e a respectiva professora de turma, de uma escola municipal de educação infantil de uma cidade do interior do estado de São Paulo.

A escolha por esta turma decorreu do fato de que nessa escola esta é a primeira faixa etária a ser atendida, sendo então o início das experiências em instituição de educação coletiva, para muitas crianças e, também, porque há uma compreensão social de que quanto menor é a criança, menos ela irá aprender e ensinar, fortalecendo exclusivamente práticas relativas apenas ao cuidar das mesmas.

Procedemos a observação participante durante 4 meses consecutivos dos momentos de brincar livre das crianças, que ocorreram às sextas-feiras, em período da manhã, nos espaços da unidade de educação infantil. A coleta foi realizada às sextasfeiras, pois este foi o dia da semana em que as crianças levavam seus brinquedos de casa para a instituição e que estava instituído, em rotina, o brincar livre. Neste dia, as crianças da turma do Maternal II da professora Alice tinha o brincar livre anunciado na rotina como 'Brincar na sala de aula', com horário entre $10 \mathrm{~h} 00 \mathrm{~min}$ às $11 \mathrm{~h} 10 \mathrm{~min}$.

Para caracterizar o espaço de sala desta turma, destaca-se que havia três mesas de seis lugares cada uma, a mesa da professora, armários, uma lousa, ventilador, espelho, lixo e um baú com brinquedos. A sala era bem colorida, com vários desenhos nas paredes e nos armários. $\mathrm{O}$ ambiente era fresco, arejado e com boa iluminação. A decoração da sala foi feita a partir de histórias trabalhadas na apostila ${ }^{4}$.

Sobre a observação participante, esta possibilita ao(a) pesquisador(a) um contato pessoal com a situação pesquisada, fazendo com que ele(a) experiencie diretamente essa situação e acompanhe as experiências diárias dos sujeitos (LUDKE; ANDRÉ, 2012). As inserções de observação participante na prática social de brincar livre ocorreram a partir de um processo de convivência com as participantes da pesquisa (crianças e professora), permeado pelo diálogo, respeito e confiança, corroborando com a proposta de "convivência metodológica" (OLIVEIRA, 2009). Compreender uma realidade, estabelecer confiança com os(as) participantes, dialogar com eles(as), ter a possibilidade de trocas de experiências e olhar a situação exercitando-se em ver a partir de outro ponto de vista, somente é possível se o(a) pesquisador(a) participar das atividades daquelas pessoas, estar junto delas.

Considerando ainda Silva, Barbosa e Kramer (2008) entendeu-se como fundamental escutar o que as crianças tinham a dizer, atentando-se ao que é dito por meio da linguagem oral, mas também ao dito pelo olhar, pelos gestos e pelo silêncio. Esta atividade exige postura humilde do adulto pesquisador(a) com a consciência de que não sabe tudo sobre crianças, exercitando-se constantemente na suspensão de crenças, ideias e concepções prévias. 
Para registro da observação participante, foram produzidos diários de campo para cada dia de coleta. Esta técnica de registro se caracteriza por ser um relato escrito daquilo que o(a) pesquisador(a) viu, ouviu, experienciou e pensou no decorrer da pesquisa (BOGDAN; BIKLEN, 1994). Este registro é um auxílio importante para a memória do(a) pesquisador(a), pois aspectos cruciais da pesquisa podem ser revelados a partir deste instrumento, permitindo um olhar aprofundado para a análise da situação pesquisada (COSTA, 2002). A partir das contribuições de Bogdan e Biklen (1994) foram descritas as ações das crianças e da professora, suas falas e gestos, buscando detalhar e respeitar as manifestações.

A análise dos dados foi realizada qualitativamente à luz do referencial teórico escolhido. A partir dos dados foram estabelecidas 3 eixos de diretrizes de análise:1. Empresto ou não empresto?; 2. Pedir, negociar ou pegar sem pedir; 3. Relações humanas no brincar. Foram respeitados todos os preceitos éticos ${ }^{5}$ no que se refere ao consentimento de participação, ao anonimato das participantes, por meio de nomes fictícios escolhidos pelas próprias participantes e à confidencialidade dos dados.

\section{Resultados e Discussão}

No eixo de análise 'Empresto ou não empresto?', as crianças vivenciaram muitas situações em que, ao interagirem com outras crianças, tiveram que decidir pelo empréstimo (partilha) de brinquedos.

Ben 10, Homem Aranha e Hulk brincam sentados à mesa da sala (sala de aula) com os brinquedos que trouxeram.

Ben 10: Homem Aranha fala - deixa eu brincar com o seu brinquedo?

Homem Aranha: Não!

Ben 10: Não?

Homem Aranha: Não, minha mãe não deixa.

Ben 10: Eu sou seu amigo, depois eu dou o meu.

Homem Aranha deu o material e começou a brincar com o brinquedo do Ben 10. Logo depois quis seu brinquedo de volta e Ben 10 rapidamente devolveu.

Ben 10, vendo que Hulk queria brincar com o super homem do Homem Aranha, perguntou:

Ben 10: Deixa ele brincar com o seu?

Homem Aranha: Não deixo! (gesticulando com a cabeça o sinal negativo e puxando forte o brinquedo para si)

Ben 10: Mas ele é seu amigo.

Pesquisadora: Mas Homem Aranha não emprestou e ficou brincando com seu brinquedo e Hulk com o dele.

Ben 10 começa a brincar com Sidney, ficam pulando e se jogando no chão da sala (Diário de Campo n. 5) 
Em cenas lúdicas como essa, muitas vezes há um olhar negativo atribuído à criança que não quer emprestar seu brinquedo ou outro objeto que esteja brincando. Carvalho, Gomes e Brunello (2009) afirmam que quanto mais velhas as crianças vão ficando, mais elas resistem em fazer pequenas coisas como, por exemplo, não querer emprestar esses suportes lúdicos. Isso na visão das autoras é fundamental para que as crianças reconheçam seus jeitos de ser. Outra posição trazida pelas autoras (2009) é que, ao dizerem não para a outra criança, querendo ficar com o objeto, as crianças confundem o meu com o eu, buscando com a posse do objeto assegurar a posse de sua própria personalidade.

Carvalho, Pedrosa e Rosseti-Ferreira (2012) anunciam que quando as crianças se opõem em alguma situação, elas constroem sua autonomia e se percebem como sujeito individual. Sendo assim, compreendemos que as situações de conflito, interesse similar pelo mesmo material lúdico entre as crianças, como no exemplo elucidado, também são importantes para elas aprenderem a se relacionar com seus pares e com os adultos. Nas relações sociais, o humano passa por diversas situações, por isso é preciso deixar que as crianças experienciem diferentes momentos, para aprenderem a conviver com outras crianças e seus diversos interesses e manifestações. As aprendizagens devem ocorrer não somente para saber emprestar ou pedir, mas também para aprenderem a se defender, argumentar, manifestar sua ideia e decisão.

Saber emprestar algo é uma aprendizagem que a criança vai adquirindo ao longo da vivência e em seus diversos círculos sociais, em vários contextos, por meio das relações estabelecidas. No momento da pesquisa essas crianças estavam passando pelo primeiro ano de ingresso na Educação Infantil. Muitas delas podem não ter sido incentivadas a partilhar seus brinquedos com outras crianças. Corsaro (2011) afirma que quando as crianças chegam à escola percebem que suas ideias de propriedade, posse e compartilhamento não são compatíveis com as situações com as quais se deparam diante da relação com seus pares, sendo estas vividas com mais intensidade no brincar.

No eixo de diretriz de análise 'Pedir, negociar ou pegar sem pedir', durante as brincadeiras, ocorreram momentos em que brinquedos foram retirados de uma criança pela outra, sem permissão, e momentos de solicitações e negociações para conseguir o objeto lúdico.

Brincando em sala com diversos brinquedos, Josi fala: Tia brinca comigo? Olha o que eu achei!

Pesquisadora: $\mathrm{O}$ que é isso?

Josi: Ele acende a luz, não sei.

Pesquisadora: Vamos dar um nome pra ele?

Josi: "João Fábrico"

Ben 10, que estava brincando com animais de plástico junto com Homem Aranha, foi andando rapidamente em direção a Josi para ver o brinquedo.

Ben 10: Deixa eu tentar fazer, por favor!

Josi entra embaixo da mesa e Ben 10 vai atrás. Ela entrega o objeto para ele. Ben 10 brinca, mas rapidamente deixa de lado e vai brincar de fazer comidinha (Diário de Campo n. 1). 
Faz parte da nossa sociedade e da nossa cultura pedir "por favor" quando para solicitar algo para outra pessoa. Nesta cena, Ben 10 manifestou algo importante no que se refere a valores sociais. Isso evidencia que, a partir das relações vivenciadas nas brincadeiras, as crianças se apropriam de elementos culturais, como comportamentos e valores pertencentes à cultura da sociedade em geral.

Quando as crianças brincam com seus pares, elas constituem o que Corsaro (2011) denominou como cultura de pares $^{6}$, ou seja, cultura construída pelas crianças enquanto estas vivenciam juntas determinadas experiências. Para ele (2002) a produção na cultura de pares não é somente uma imitação ou reprodução da cultura do adulto. Pelo contrário, as crianças no momento em que reproduzem a cultura adulta, além de se inserirem nesta cultura, participam da produção da cultura de pares, cultura que é da infância. Neste sentido, durante a brincadeira, ao pedir "por favor", Ben 10 não somente reproduziu um elemento da cultura adulta, global, como também se apropriou desta para a produção infantil. Carvalho e Pedrosa (2002) também discorrem sobre esse assunto e afirmam que quando as crianças trazem valores e conceitos da macrocultura para as brincadeiras elas têm a oportunidade de questioná-los, de reconstruí-los e fortalecê-los, além de assumirem um papel ativo de transmissoras para seus pares.

Também foi destaque a presença de várias cenas lúdicas em que as crianças se articularam dentro do contexto da brincadeira, investindo em argumentos e negociações para conseguir o brinquedo. Isso é exemplificado quando Ben 10 negociou a entrada de Hulk na brincadeira com o empréstimo do brinquedo trazido por ele.

Em sala, Homem Aranha e Ben 10 brincam embaixo da mesa com o brinquedo super homem, que Homem Aranha trouxe de sua casa.

Hulk quer entrar embaixo da mesa e segurando seu capitão América pede ao Ben 10 para entrar.

Hulk: Posso entrar?

Ben 10: Pode. Deixa eu brincar com seu brinquedo?

Hulk empresta seu brinquedo e as três crianças ficam brincando juntas (Diário de Campo n. 5).

A troca de objetos é uma estratégia utilizada pelas crianças para serem aceitas nos grupos, nas brincadeiras (BORBA, 2005). E isso elas aprendem ao brincar juntas. A vontade de participar da brincadeira, de entrar embaixo da mesa junto com Ben 10 e Homem Aranha e entrar na dinâmica lúdica pode ter contribuído para que Hulk emprestasse facilmente seu brinquedo. São em situações como essas que as crianças estabelecem relações de solidariedade e de amizade, pois quando brincam juntas, elas precisam construir e manter um espaço interativo, partilhando objetos, valores, conhecimentos e negociando com seus pares (BORBA, 2007).

Brougère (2010) afirma que o desejo de utilização pelo brinquedo faz com que as crianças passem por experiências de posse e de negociações com as outras crianças, fazendo com que elas se relacionem e interajam ainda mais durante as brincadeiras. Além da brincadeira, o brinquedo também acompanha as crianças em suas construções de relações sociais, como, por exemplo, nas negociações (SARMENTO, 2003). 
No terceiro eixo de análise 'Relações humanas no brincar', as crianças se relacionaram com seus pares ou com adultos, pois ao brincar elas manifestaram interesse por estar com o(a) outro(a) e, muitas vezes, precisaram dele(a) para validar suas ideias e compor os personagens e enredo da brincadeira. Isso pode explicar o fato de que, em todos os dias da coleta de dados, foi presenciado o brincar com alguém. Quando vão para a escola, as crianças passam a conviver diariamente com um mesmo grupo de crianças. Nesse convívio, a cada dia, elas se conhecem melhor, pois se relacionam nas diversas atividades da rotina da instituição. Dentre essas atividades, as brincadeiras são um espaço privilegiado para que as crianças aprendam a se relacionar, se conheçam melhor e estreitem seus vínculos de amizade.

Ben 10 sentado no gira-gira do pátio pergunta para Miguel:

Ben 10: Você quer ir na floresta?

Miguel senta no gira-gira, os dois se olham e giram um pouco.

Miguel sai do brinquedo e vai no outro gira-gira. Ben 10 vai atrás dele rapidamente.

Uma criança da outra turma senta no gira-gira em que Ben 10 estava sentado antes.

Ben 10 vê a criança sentada e vai até ela.

Ben 10: Fala gesticulando com as mãos - É meu carro, é meu carro!!!

Mas a criança fica sentada e Ben 10 volta para o gira-gira que o Miguel estava (Diário de Campo n. 10).

Entre Ben 10 e Miguel parece existir uma relação de empatia, afinidade e aproximação, identificada por brincaram juntos várias vezes durante o período da pesquisa de campo. Essa relação contribuiu com a atitude de Ben $10 \mathrm{em}$ voltar a ficar junto de Miguel no outro brinquedo de gira-gira.

Através de experiências conjuntas, as crianças vão marcando suas preferências por determinadas brincadeiras e parceiros, construindo suas identidades pelo pertencimento a um grupo, pelas posições que assumem junto aos companheiros, pelos papéis que adotam nas brincadeiras, bem como pelas ações que desenvolvem associadas às diferentes brincadeiras das quais participam (BORBA, 2005, p. 124).

A autora (2005) explica que inicialmente as crianças pequenas não brincam juntas com determinadas crianças porque estas são suas amigas. Pelo contrário, elas se tornam amigas brincando juntas e isso depois de certa aproximação e vínculo se torna um parâmetro para escolherem com quem brincar. Corsaro (2011) também discorre sobre esse assunto e afirma que as amizades são construídas a partir da participação das crianças em seus mundos sociais e culturas de pares. Para as crianças pequenas, a amizade serve para as funções integradoras como acesso a um grupo, construção de solidariedade e proteção do espaço interativo. 
Nesta cena, Ben 10 não parecia ter uma relação de amizade com a criança da outra sala, talvez por ela não pertencer ao seu mundo social, do seu grupo, e isso pode ter feito ele se distanciar e desistir do brinquedo. Quando as crianças já estabeleceram seus vínculos de amizade, a convivência e as trocas de experiências ocorrem de modo mais profundo durante as brincadeiras e possibilitam que elas aprendam enquanto estão juntas, ou seja, enquanto brincam.

$\mathrm{Na}$ sala, Hulk pega a máscara de tigre de pelúcia que, na verdade é uma touca que o Miguel trouxe, e entrega ao Sidney em troca da máscara do Batman.

Sidney vem assustar Moranguinho e eu com a máscara de tigre, mas depois não quer mais brincar e entrega para Moranguinho dizendo:

Sidney: É a sua vez.

Sidney quer pegar de volta a máscara do Batman que está com Hulk e diz: Sidney: É a minha vez! É a minha vez!

Moranguinho com a máscara de tigre sai correndo atrás de Sidney pela sala.

Professora Ana diz: Na sala não pode correr, porque o espaço é pequeno e cai.

Os dois imediatamente param de correr.

Ben 10 pega a máscara que está com Moranguinho, tirando do seu rosto sem pedir, mas ela não diz nada e sai correndo junto com ele e Sidney.

Josi pergunta para Ben 10: Deixa eu por um pouquinho?

Ben 10 não diz nada e continua correndo pela sala junto com Sidney e Moranguinho (Diário de Campo n. 6).

Hulk e Sidney utilizaram estratégias comuns ao contexto da brincadeira para alcançar o objetivo de ambos, ou seja, utilizar a máscara do Batman. Estes momentos de brincar livre potencializam aprendizagens como essa, e, ao representarem e expressarem seus pensamentos, a partir de sua convivência e experiências de troca com seus pares, professora ou familiares, Hulk e Sidney podem ter contribuído com a aprendizagem de outras crianças que estavam envolvidas nessa brincadeira.

De acordo com os autores Sarmento (2003), Borba (2005) e Brougère (2010) a brincadeira é espaço para socialização, para aprendizagem da sociabilidade. No brincar juntas, as crianças aprendem a dominar a relação com o outro, exercitam a decisão e a invenção. Porém, essa aprendizagem ocorre de acordo com o tempo de cada criança, por isso é aleatória e incerta (BROUGÈRE, 2010).

O lúdico proporciona novas experiências de aprendizagem sobre a vida e a realidade, por isso, Borba (2007, p. 41) explica: "Brincar com o outro, portanto, é uma experiência de cultura e complexo processo interativo e reflexivo que envolve a construção de habilidades, conhecimentos e valores sobre o mundo”. 


\section{Algumas considerações}

Considerando os resultados encontrados, compreendemos as brincadeiras chamadas de livres como oportunidades para as crianças construírem e experienciarem processos de ensinar e de aprender. Essas crianças vivenciaram múltiplos momentos em que brincaram junto com o outro, manifestaram ideias, interesses e decisões.

No estar junto partilharam situações harmoniosas e conflituosas, ambas importantes para o processo de aprendizagem e construção da autonomia. Representaram seus pensamentos em brincadeiras simbólicas, as preferidas por este grupo infantil; reinterpretaram personagens, tomaram decisões, manifestaram escolhas, pediram os brinquedos de seu interesse, negociaram as brincadeiras e materiais, negaram um pedido realizado por alguém. Além disso, construíram estratégias para participarem das brincadeiras que, em sua maioria, foram realizadas em duplas ou pequenos grupos contribuindo, assim, para intensificar relações e laços de sociabilidade e de amizade entre as crianças. Para criarem o contexto brincante, compartilharam suas ideias, maneiras de brincar e explorar os objetos lúdicos, fazendo com que a cultura lúdica ${ }^{7}$ fosse fortalecida por esse grupo de crianças.

Com essas experiências elas foram autoras nesse processo de ensinar e de aprender e tiveram possibilidades para construírem juntas uma maneira para conviverem nesse grupo e se relacionarem entre elas e com adultos. Carvalho, Pedrosa e Rosseti-Ferreira (2012, p. 164) ao discutirem sobre as relações entre as crianças afirmam:

Cada relação, seja entre duas crianças, seja entre três ou mais, é um espaço de construção de conhecimentos e sentimentos compartilhados, de jogos e brincadeiras e maneiras de usar os objetos, de significados de palavras e outros recursos comunicativos; o que já é compartilhado, por sua vez, facilita novas construções, ampliando e modificando o sentido que a criança dá ao mundo e sua maneira de se colocar nele, diferenciando-se como uma pessoa, um indivíduo, membro de um grupo social que tem características próprias.

Esse estudo ainda evidenciou que na Educação Infantil, as crianças vivenciam processos educativos, para além do que está previsto nos currículos. Entretanto, as aprendizagens ocorridas no momento do brincar, por exemplo, ainda não são consideradas relevantes, pois muitas vezes nem são observadas, acompanhadas e analisadas pela/o professor/a. Neste contexto de pesquisa, colocamos em destaque que a professora teve participações pontuais nas cenas lúdicas, majoritariamente quando as crianças iniciavam situações de conflito por brinquedos. Outro aspecto identificado com esta pesquisa de campo, que merece atenção, mas que não foi objeto de análise neste artigo refere-se às poucas oportunidades para a brincadeira livre fora de sala de aula.

Oliveira e Mizukami (2002) apontam que os profissionais da educação ficam limitados a refletir sobre as aprendizagens ocorridas apenas dentro da sala de aula quando o(a) professor está ensinando um conteúdo pontual. As autoras (2002) também afirmam que os sistemas de avaliação contribuem ainda mais para isso, fazendo com que os(as) professores(as) selecionem os conteúdos visando os resultados para as avaliações. Contudo, ao participarem de pesquisa realizada pelas autoras (2002) as 
crianças citam diferentes aprendizagens ocorridas na escola, principalmente as que caracterizam a relação com o outro. Na escola a criança é solicitada a responder a situações variadas, não somente referentes às atividades escolares, mas também às situações de socialização no contato com outras crianças, no estabelecimento de vínculos afetivos e na observação de regras próprias da escola (OLIVEIRA; MIZUKAMI, 2002).

O brincar livre, como elucidado nessa investigação, se caracteriza como um importante momento onde as crianças se relacionam entre si, trocam e vivenciam novas experiências juntas. Quando planejados e acompanhados pelos professores(as), esses momentos podem contribuir para que a escola seja, além de local de apropriação de conhecimentos escolares, sistematizados, seja local para se viver experiências de infância, de cultura e de formação para a vida.

\section{Referências}

BOGDAN, R. C.; BIKLEN, S. K. Notas de campo. IN: BOGDAN, R. C.; BIKLEN, S. K. Investigação qualitativa em educação. Porto: Porto Editora, 1994, p. 150-175.

BORBA, A. M. Culturas da infância nos espaços-tempos do brincar: um estudo com crianças de 4 a 6 anos em instituição pública de educação infantil. 298 p. Tese (Doutorado em Educação). Universidade Federal Fluminense, Niterói, 2005.

. O brincar como modo de ser e estar no mundo. In: BRASIL. Ensino Fundamental de 9 anos: orientações para a inclusão de crianças com seis anos de idade. 2. ed. Brasília, 2007. p. 33-45.

BRASIL. Diretrizes Curriculares Nacionais para a Educação Infantil. Brasília: MEC, SEB, 2010. Disponível em <http://portal.mec.gov.br/index.php?option=com_docman\&task=doc_ download\&gid=9769\&Itemid $>$. Acesso em: 15 fev. 2016.

BROUGÈRE, G. Lúdico e educação: novas perspectivas. Linhas críticas. Brasília, v. 8, n. 14, jan./jun. 2002.

. Brinquedo e cultura. São Paulo: Cortez, 2010.

CARVALHO, A. M. A.; PEDROSA, M. I. Cultura no grupo de brinquedo. Estudos de Psicologia. Natal, v. 7, n. 1, p. 181-188, jan./jun. 2002.

CARVALHO, A. M. A.; PEDROSA, M. I.; ROSSETI-FERREIRA, M. C. Aprendendo com a criança de zero a seis anos. São Paulo: Cortez, 2012.

CARVALHO, R.; GOMES, S. H. P.; BRUNELLO, R. É meu, é seu, é nosso, ou é da creche? In: ROSSETI-FERREIRA, M. C.; MELLO, A. M.; VITORIA, T.; GOSUEN, A.; CHAGURI, A. C. (orgs.). Os fazeres na Educação Infantil. 11a ed. São Paulo: Cortez, 2009, p. 67-68.

CORSARO, W. A. A reprodução interpretativa no brincar ao "faz-de-conta" das crianças. Educação, Sociedade \& Culturas. Porto, n. 17, p. 113-134, jul./ago. 2002.

. Sociologia da infância. $2^{\mathrm{a}}$ ed. Porto Alegre: Artmed, 2011.

COSTA, S. A. O Diário de Campo como dialética intersubjetiva. In: WHITAKER, Dulce C. A. (org.). Sociologia Rural: questões metodológicas emergentes. Presidente Venceslau: Letras à Margem, 2002, p. 151-158.

DORNELLES, L. Infâncias que nos escapam. São Paulo: Vozes, 2008.

EMERIQUE, P. S. Brincaprende: dicas lúdicas para pais e professores. Campinas: Papirus, 2003. 
FREIRE, P. Pedagogia da Autonomia: saberes necessários à prática educativa. São Paulo: Paz e Terra, 2005.

FRIEDMANN, A. Linguagens e culturas infantis. São Paulo: Cortez, 2013.

GOBBI, M. A.; PINAZZA, M. A. (orgs.). Infância e suas linguagens. São Paulo: Cortez, 2014.

LUDKE, M.; ANDRÉ, M. E. D. A. Pesquisa em educação: abordagens qualitativas. São Paulo: E. P. U., 2012.

MINAYO, M. C. de S. Ciência, técnica e arte: o desafio da pesquisa social. In:

Social: teoria, método e criatividade. Petrópolis, RJ: Vozes, 1994, p. 9-29. Pesquisa

OLIVEIRA, M. L. de. Escola não é lugar de brincar? In: ARANTES, V.A. Humor e alegria na educação. São Paulo: Summus, 2006, p 75-102.

OLIVEIRA, M. W. Pesquisa e trabalho profissional como espaços e processos de humanização e de comunhão criadora. Cad. CEDES v. 29, n. 79, Campinas, Setembro/Dezembro, 2009, p. 1-7.

OLIVEIRA, M.W., GONÇALVES E SILVA, P. B.. Leituras de artigo de Fiori, com a intenção de despertar outras leituras. IN: BRASIL. Ministério da Saúde. II Caderno de educação popular em saúde. Brasil: Ministério da Saúde, 2014, p. 49-54.

OLIVEIRA, M. W.; SILVA, P. B. G.; GONÇALVES JUNIOR, L.; MONTRONE, A. V. G.; JOLY, I. Z. L.. Processos educativos em práticas sociais: reflexões teóricas e metodológicas sobre pesquisa educacional em espaços sociais. In: OLIVEIRA, M. W.; SOUSA, F. R. (org.). Processos educativos em práticas sociais: pesquisa em educação. São Carlos: EduFSCar, 2014, p. $15-24$.

OLIVEIRA, R. M. M. A. de.; MIZUKAMI, M. da G. N. Na escola se aprende de tudo. In: MIZUKAMI, M. da G. N.; REALI, A. M. (org.). Aprendizagem profissional da docência: saberes, contextos e práticas. São Carlos: EdUFCar, 2002. p. 229-256.

SANTOS NETO, E.; ALVES, M.A.; PAULO da SILVA, M. R. Por uma Pedagogia da Infância Oprimida: As crianças e a infância na obra de Paulo Freire. EccoS Revista Científica, São Paulo, n. 26, Julho/Dezembro, 2011, p. 37-58.

SARMENTO, M. J. As culturas da infância nas encruzilhadas da $2^{\text {a }}$ modernidade. Braga: Instituto de Estudos da Criança, Universidade do Minho, 2003.

SILVA, J. P. da; BARBOSA, S. N. F.; KRAMER, S. Questões teórico-metodológicas da pesquisa com crianças. IN: CRUZ, S. H. V. (Org.). A criança fala: a escuta de crianças em pesquisas. São Paulo: Cortez, 2008, p. 79-101.

SOMMERHALDER, A.; ALVES, F.D. Jogo e Educação da Infância: muito prazer em aprender. Curitiba: CRV, 2011.

\section{Notas}

\footnotetext{
${ }^{1}$ Oliveira et al. (2014) destacam que prática social é educativa e se constitui da relação, união que ocorre entre as pessoas, seja em um local definido ou não, na qual estas ao conviverem umas com as outras transmitem, recebem e (re)elaboram saberes, crenças e valores, além de vivenciarem novas experiências que serão mantidas e relembradas ao longo da vida.

2 "Entenda-se que cultura no singular não se refere a uma cultura universal, tampouco superior, mas ao ambiente em que diferentes e até mesmo divergentes visões de mundo se expõem, cruzam, identificam, divergem, contrapõem, dialogam, se fazem e se refazem" (OLIVEIRA; GONÇALVES e SILVA, 2014, p. 53).

${ }^{3}$ Denominação da Rede Municipal de Ensino para turmas desta faixa etária.
} 
${ }^{4}$ A Educação Infantil municipal é apostilada.

${ }^{5}$ Aprovada pela Secretaria de Educação do Município e pelo Comitê de Ética em Pesquisa com Seres Humanos da Universidade.

${ }^{6} \mathrm{O}$ autor define cultura de pares “[...] como um conjunto estável de atividades ou rotinas, artefatos, valores e preocupações que as crianças produzem e compartilham em interação com as demais” (CORSARO, 2011, p. 128).

${ }^{7}$ A cultura lúdica é um conjunto de regras, características, significações próprias da brincadeira e que as crianças adquirem quando brincam. (BROUGÉRE, 2002).

* Mestre em Educação pela Universidade Federal de São Carlos, São Carlos, São Paulo, Brasil.

** Professora doutora da Universidade Federal de São Carlos, São Carlos, São Paulo, Brasil.

*** Professor doutor da Universidade Federal de São Carlos, São Carlos, São Paulo, Brasil.

\section{Correspondência}

Aline Sommerhalder - Universidade Federal de São Carlos, CECH - Departamento de Teorias e Práticas Pedagógicas - DTPP. Rodovia Washington Luís, km 235 - SP-310, Guanabara. CEP: 13565905. São Carlos, São Paulo, Brasil.

E-mail: linicolielo@hotmail.com - sommeraline1@gmail.com - fdalves@ufscar.br

Recebido em 17 de maio de 2016

Aprovado em 12 de junho de 2017 
